\title{
Glycogen Rich Clear Cell Carcinoma of Breast
}

\author{
Malla S, ${ }^{1}$ Shakya G, ${ }^{1}$ Regi $S,{ }^{2}$ Mudvari DS ${ }^{2}$ \\ ${ }^{1} \mathrm{NPHL}$, Teku, Kathmandu, Nepal, ${ }^{2} \mathrm{Om}$ Hospital, Kathmandu, Nepal
}

\section{ABSTRACT}

\begin{abstract}
A 37 years old woman presented with a palpable mass in outer upper quadrant of the right breast. Excision biopsy showed Glycogen rich clear cell carcinoma (GRCCC) based on histological, PAS staining and immunohistochemical staining findings Histologically, most of tumor cells were clear cell type with variable intracytopasmic PAS positivity Immunohistochemically, the tumor was positive for progesterone receptor and vimention and foceally positive for cytokeratin and negative for estrogen receptor and S100. The patient underwent right quadrantectomy with right axillary clearance. This case was in stage IIa (T2NOMx) and Elston and Ellis histological grade 2 (Scores $3+2+1=6$ ). GRCCC is a rare variant of breast carcinoma, with incidence calculated to be 1.4 to $3 \%$ and reports indicated a poorer prognosis for patient with GRCCC than those with usual breast cancer.

Key words: breast, cancer glycogen rich clear cell carcinoma
\end{abstract}

\section{INTRODUCTION}

Glycogen Rich Clear Cell Carcinoma (GRCCC) is a rare variant of the breast carcinoma with incidence calculated to be 1.4 to $3 \% .^{1}$ At least $90 \%$ of the neoplastic Cells of GRCCC have abundant clear cytoplasm containing glycogen. Minor component of eosinophilic granular cytoplasm may be present which suggest aprocrine differentiation. Scant amount of mucin may be seen in some cases. Growth pattern is usually that of usual infiltrating ductal carcinoma. Other patterns may be lobular, tubular and medullary type. Intraductal clear cell component may be present. These tumors are PAS positive, diastase sensitive and fat stain negative. Immunohistochemical staining of the tumor cells are variably positive for cytokeratin, progesterone receptors, gross cystic disease fluid protein -15 (GCDFP15), neuron specific enolase, chromogranin and S100 protein and negative for estrogen receptor, smooth muscle actin, CD31 and CD34. ${ }^{2-6}$ Glycogen-rich clear cell mammary malignant myoepithelioma is a variant of GRCCC which shows coexpressioin of vimentin, smooth muscle actin, epithelial membrane antigen, S-100 protein and cytokeratin as evidence of myoepithelial cell tumor.

\section{CASE REPORT}

A 37 years old female patient from Lamjung came to Om hospital with a complaint of breast mass at right upper outer gradrant. Excission biopsy was done followed by right quadrantectomy and right axillary clearance.

\section{Gross features}

Excisional biopsy: a single encapsulated mass measuring $2.5 \times 2 \mathrm{~cm}$. cut section shows solid areas with areas of haemorahage. Entire specimen submitted.

Right quadrantectony specimen: consists of yellow mammary tissue $(9 \times 7 \mathrm{~cm})$ with skin flap $(1 \times 4 \mathrm{~cm})$ cut section shows no obvious mass. Representative sections submitted.

Right axillary clearance specimen: consists of yellow adipose tissue $5 \times 5 \mathrm{~cm}$ with 7 lymph nodes. The largest one measures $3 \times 2 \mathrm{~cm}$. Entire specimen submitted.

Correspondence: Dr. Geeta Shakya, Chief Consultant Pathologist NPHL, Teku, Kathmandu, Nepal. Email: nphl@wlink.com.np 


\section{Microscopic features}

Excision biopsy: section shows breast tissue with tumor cells arranged in nests, trabeculae and singly dispersed. Nests are separated by fibrous septa. Tumor cells are moderately pleomorphic, have sharply defined border and polygonal contours. Cytoplasm is clear in more than $90 \%$ of cells and finely granular in few cells. Nuclei are hyperchromatic with clumpled chromatin and prominent nucleoli. Occassional mitosis is also seen. Necrosis and lymphovascular invasions are absent. Intervening stroma shows moderate degree of chronic inflammatony cells infiltration. Surrounding breast tissue shows fibrocystic change with apocrine metaplasia.

Quadrantectomy specimen: Section from breast tissue shows existence of residual tumor cells, similar to those in excision biopsy with tubular formation less than $10 \%$ and mitosis is very occasional. All four margins (inferior, superior, lateral and medial) are free from tumor. Right axillary nodes: show reactive change.
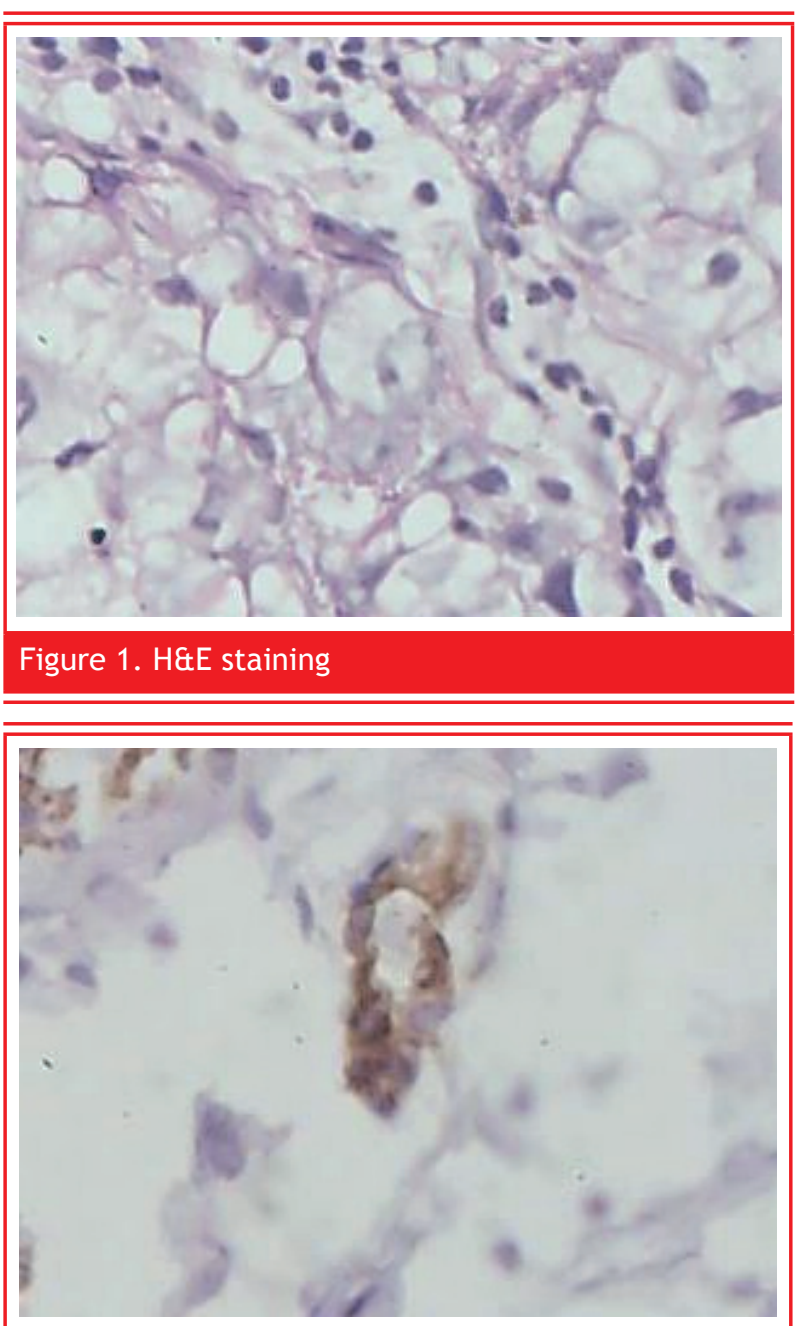

Figure 3. Cytokeratin
Special stain: (PAS staining): intracytoplasmic PAS positivity in tumor cells are variable.

Immunohistochemical staining:

- Progesterone receptor: positive

- Vimentin: positive

- Cytokeratin focally: positive

- Estrogen receptor: negative

- S100: negative

Diagnosis:

Moderately differentiated Glycogen rich clear cell carcinoma in breast. Elston and Ellis histological grade 2 $(3+2+1=6)$ TMM stage IIA (T2 NO Mx).

\section{DISCUSSION}

Glycogen rich clear cell carcinoma of the breast is a rare tumor and as far as we are aware it is the first reported case in Nepal. Though more than $90 \%$ tumor cells showed clear cell cytoplasm and intracytoplasmic
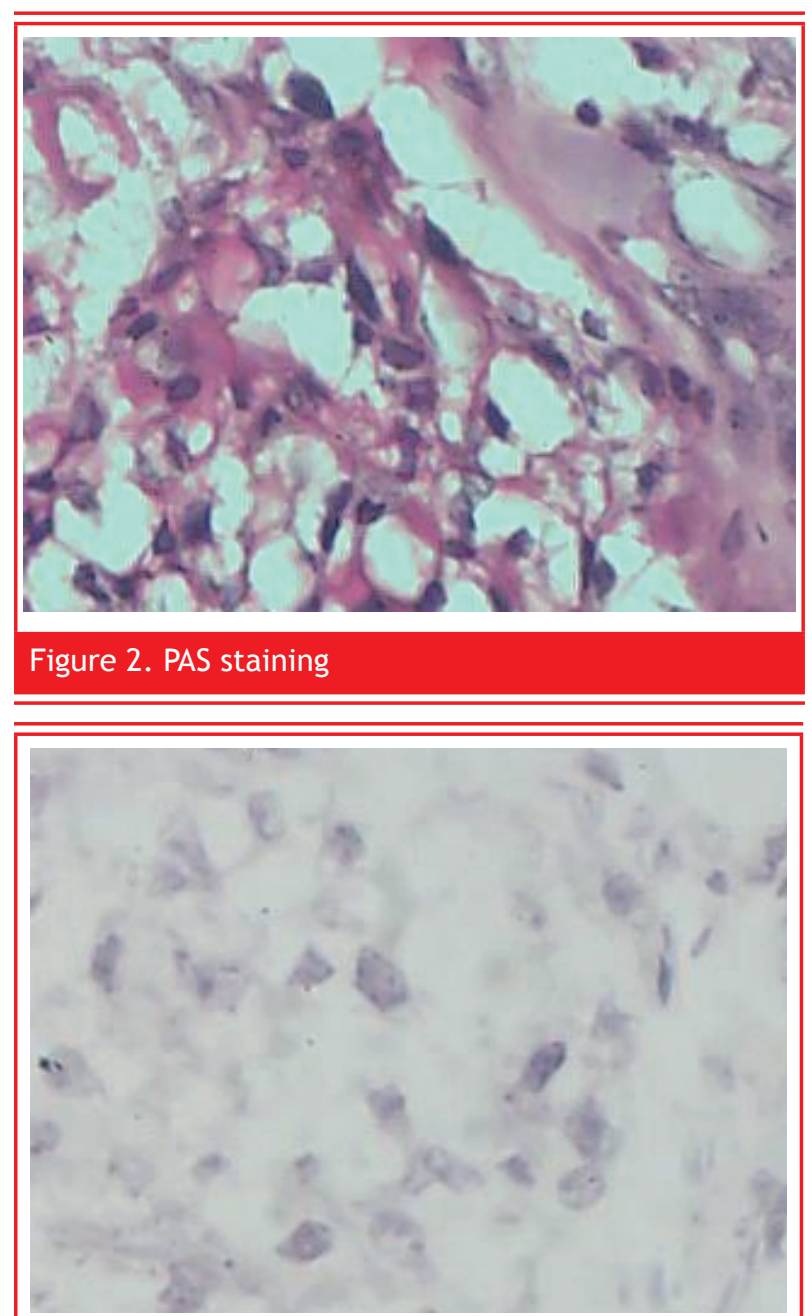

Figure 4. ER negative 


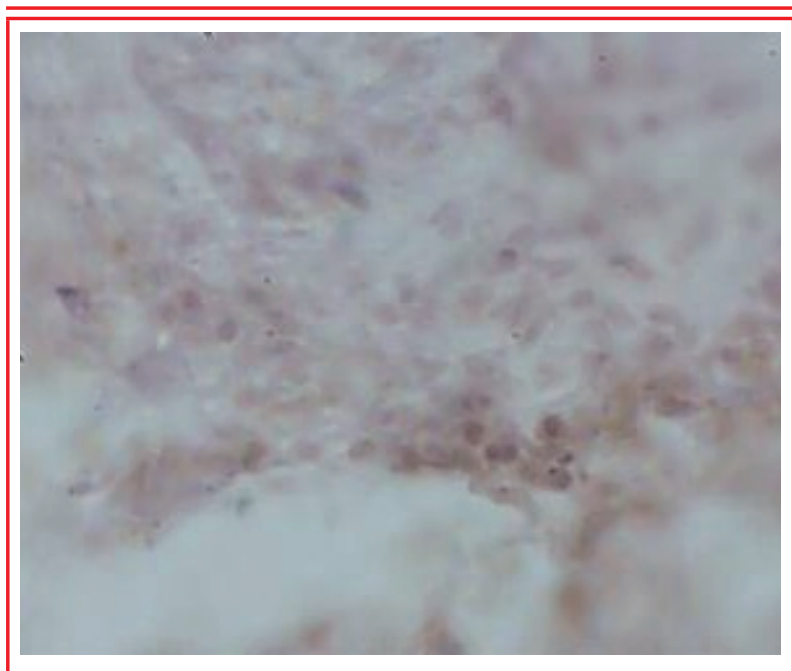

Figure 5. PR positive

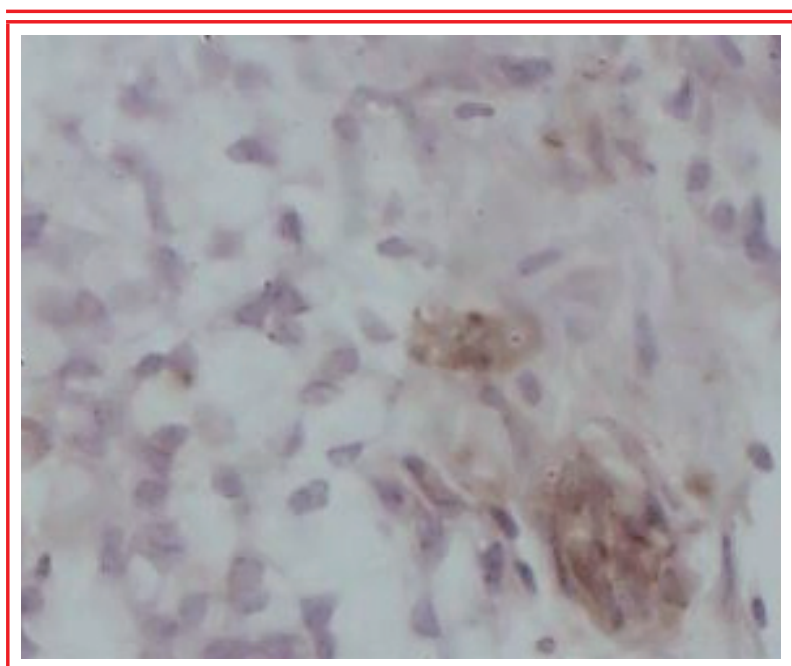

Figure7.Vimentin Positive

PAS positivity in tumor cells were variable. This variability could be due to solubility of glycogen. Few cells showed eosinophilic granular cytoplasm which suggest apocrine differentiation. Hyan JS et al. reported a case of Glycogen rich clear cell mammary malignant myoepithelioma in 43 yrs old woman. ${ }^{6}$ Histologically, the tumor composed of clear cells with abundant cytoplasmic glycogen particles. Immunohistochemically, these tumors showed co-expression of vimentin, smooth muscle actin, epithelial membrane antigen, S100 protein and cytokeratin as evidence of myoepithelial cell tumor. The pathological staging of the patient was IIB (pT3NOMO) and Histological grade was 2 . The present reported case showed immunohistochemically positive for progesterone receptor, vimentin and focally for cytokeratin but negative for Estrogen receptor and S100 protein. Other markers like Epithelial membrane Antigen, smooth nuscle Actin could not be done due to non availability in

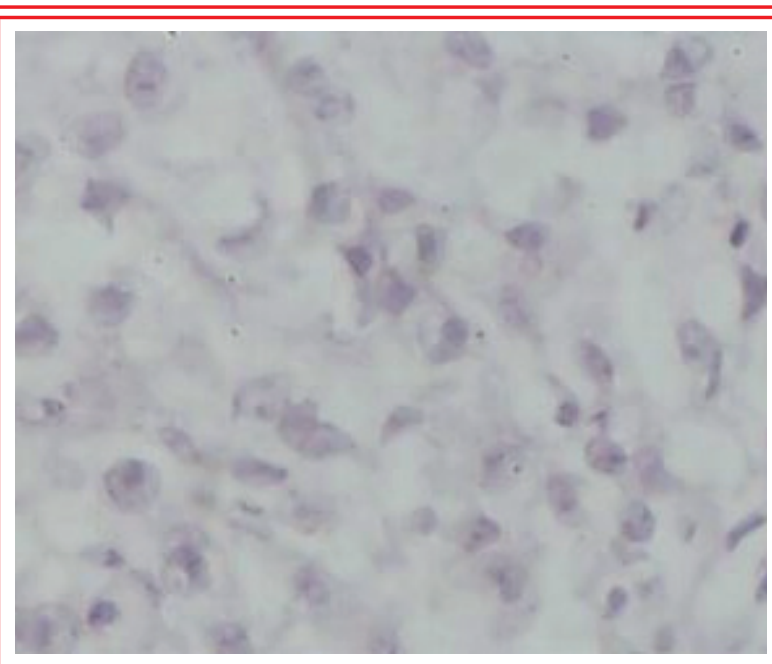

Figure 6. S100 negative

the market. Since the present reported case is positive for vimentin and cytokeratin there was possibility that the case could be glycogen rich clear cell carcinoma of myoepithelial origin, but histologically most cells are of single cells type. Myoepithelial tumors usually show two cell types. Histological with supplemental studies showed that this rare case reported was Glycogen rich clear cell carcinoma. The reports indicated poor prognosis for patient with GRCCC than those with usual breast cancers. ${ }^{3}$

\section{REFERENCES}

1. Kim WS, Lee WM, Hong EK, Park MH, Lee ID. Fine needle aspiration cytology of glycogen-rich clear cell carcinoma of the breast: A report of two cases. Korean J cytopathology 1998 Dec;9(2):213-9.

2. Kawashaki A, Mimatsuk K, OidaT, KubaiY, KatsuraY, Amano SF. A case of glycogen-rich clear cell carcinoma of the breast. Journal of Japan Surgical Association 2003;64(7): 1593-6.

3. Jacqueline KT, Eric O, Simon B. Pathologic quiz case: Mass in the right breast. Archives of Pathology and Laboratory Medicine 2003;127(12):1629-30.

4. Suzanne ES, Carlos TE, Ian PT, Elaine EW, Brain W. Clear cell carcinomaof the breast with immunohistochemical evidence of divergent differentiation. Annals of Diagnostic Pathology 2002 Aug;6(4):250-6

5. Sorensen FB, Paulsen SM. Glycogen rich clear cell carcinoma of the breast: a solid variant with mucus, a light microscopic immunohistochemical and ultra structural study of a case. Histopathology 1987 Aug;11(8):857-69.

6. Hyun JS, Sung HS, Sang YL, Woo SM. Glycogen-rich clear cell mammary malignant myoepithelioma. The Breast 2004 Dec;13(6):506-9. 